\title{
A IMPORTÂNCIA DA EDUCAÇÃO INFANTIL COMO BASE FUNDAMENTAL AO PROCESSO DE APRENDIZAGEM EM ITAPURANGA - GO
}

\author{
ARLETE FELIX VIEIRA SILVA
}

\section{RESUMO}

Ao longo das últimas décadas foram acumulando evidencias em relação à importância da Educação Infantil com base fundamental ao Processo de Aprendizagem em Itapuranga -GO. Esta pesquisa apresenta uma análise teórico-prática e suscita reflexões capazes de contribuir com o processo de ensino-aprendizagem nas escolas da Rede Municipal de Ensino do supracitado Município onde o estudo de caso foi desenvolvido. Foram entrevistados vinte e seis professores que atuam nas escolas do Município, apresentou e analisou os conceitos da aprendizagem na Educação Infantil, seus colaboradores, seus desfavores numa perspectiva efetiva de qualidade para essa etapa educacional no Município / Rede de Pública Municipal. A categoria teórica foi tomada com base nas teorias de Jean Piaget (1896), Henri Wallon (1879), dentre outros. Desse modo, identificou-se a importância da Educação Infantil através do processo de ensino-aprendizagem que articulam diversas lógicas entre os interlocutores da Educação com base nas dimensões de integração, estratégia e subjetivação - base fundamental para experiências educacionais que imprimem caráter de continuidade.

Palavra-chave: Educação Infantil, Aprendizagem, Ensino, Escola, Infância.

\begin{abstract}
Over the last few decades, they have accumulated evidence regarding the importance of Early Childhood Education with a fundamental basis for the Learning Process in Itapuranga -GO. This research presents a theoreticalpractical analysis and elicits reflections capable of contributing to the teachinglearning process in the schools of the Municipal Education Network of the aforementioned Municipality where the case study was developed. We interviewed twenty - six teachers who work in the schools of the Municipality, presented and analyzed the concepts of learning in Early Childhood Education, its employees, their disadvantages in an effective perspective of quality for this educational stage in the Municipality / Municipal Public Network. The theoretical category was taken based on the theories of Jean Piaget (1896), Henri Wallon (1879), among others. and on the importance of developing new skills and competences so that there is a broader perception of the universe of each student, reassessing the multiple methodological attitudes so as to facilitate the appropriation of the culture that makes possible the payment of the human being. Thus, we identified the importance of Early Childhood Education through the teaching-learning process that articulate several logics among the interlocutors of Education based on the dimensions of integration, strategy and subjectivation - fundamental basis for educational experiences that imply continuity.
\end{abstract}

Keywords: Early Childhood Education, Learning, Teaching, School, Childhood. 


\section{INTRODUÇÃO}

A Educação Infantil é um dos assuntos de maior peso no meio educacional na contemporaneidade brasileira. A mesma é olhar de pesquisadores estudiosos no campo educacional, por entender que, por ser 0 início, a base de todos os demais processos futuros, a mesma deve ser oferecida com a melhor qualidade possível.

Partindo da revisão do contexto escolar na atualidade, muitas escolas continuam dominadas pela concepção pedagógica tradicional, onde a Educação Infantil ainda é tida como assistencialista, o ensino muitas vezes é realizado de forma empírica tradicionalista acarretando grandes consequências negativas, principalmente para aquele que é o alvo da aprendizagem: o educando.

A Lei de Diretrizes e Bases - 9394/96 de 20 de dezembro de 1996 surge como um importante princípio norteador do processo da pré-escola no âmbito educacional do Ensino Fundamental. Propõe uma reflexão e ação acerca do ensino onde a família e a instituição escolar deverão atender e cumprir com seus respectivos deveres no que diz respeito ao cuidar e educar as crianças de 0 (zero) a 5 (cinco) anos de idade.

Nesse sentido, devido à importância deste tema sobre a Educação Infantil, objeto de estudo deste trabalho, essa pesquisa busca compreender como a mesma vem sendo oferecida na prática educativa nas escolas da rede municipal do Município de Itapuranga - Goiás..

Assim, o objetivo geral passa a ser em analisar como o processo dessa tão importante etapa educacional vem sendo realizada e contribuindo com os rumos no tocante a aprendizagem em todo seu bojo e relevância ao crescimento e transformação do ser humano ou sua estagnação, e para tanto, será discutido os conceitos históricos da evolução da criança, a visão familiar e a contribuição da formação do docente e os parâmetros legais que embasam essa tão importante base educacional, que é atualmente denominada de Educação Infantil.

"A atual realidade da Educação Infantil na Rede Pública Municipal de Itapuranga - GO" foi o marco de nossa pesquisa enquanto mola propulsora para responder as muitas inquietudes que nos acompanharam ao longo de nossos estudos, assim como servirá para muitos outros pesquisadores ou curiosos 
nesta área para obter uma compreensão atualizada da realidade educacional deste Município, bem como inspirar para a continuidade/aprofundamento em busca de resultados extraordinários para o atual cenário educacional.

\title{
DESENVOLVIMENTO
}

\section{A EDUCAÇÃO INFANTIL NO SEU PERCURSO HISTÓRICO}

Ao pensar em ensino aprendizagem, vários fatores como social, familiar, físico, pedagógico e entre outros, devem ser levados em consideração.

A Educação Infantil caracteriza-se como sendo a primeira etapa de ensino. Traz em seu bojo uma necessidade de ser vista sob um olhar de suma importância por parte da família, educadores e órgãos governamentais educacionais, para uma efetivação sólida na formação social e educacional do sujeito em seus primeiros anos escolares, como prevenção de futuros problemas de aprendizagens educacionais. Por longos períodos a educação Infantil foi direcionada somente o seu primeiro âmbito social ao qual a criança pertencia, pois junto a sua espécie ela aprendia com os adultos hábitos e costumes tornando-se membro desse grupo social.

Para Craidy e Kaercher (2011):

\begin{abstract}
Durante muito tempo, a educação da criança foi considerada uma responsabilidade das famílias ou do grupo social ao qual ela pertencia. Era junto aos adultos e outras crianças com os quais convivia que a criança aprendia a se tornar membro deste grupo, a participar das tradições que eram importantes para ele e a dominar os conhecimentos que eram necessários para sua sobrevivência material e para enfrentar as exigências da vida adulta. (CRAIDY e KAERCHER, 2001 P. 13)
\end{abstract}

Ao pensar na criança como responsabilidade só da família, e do meio social a qual a mesma está inserida, limita se uma construção ampla de conhecimentos na sua formação enquanto cidadão. O que relata ainda as autoras que só por volta dos séculos XVI e XVII, é quem tende a surgir às primeiras instituições de ensino voltadas a educação infantil, e juntamente a esse processo um modelo pedagógico moderno resultante a expansão europeia e a invenção da imprensa que fortalece a necessidade da leitura e escrita. (CRAIDY e KAERCHER, 2001). 
Para Áries (1981), a ideia de infância como um período único e peculiar é muito importante na formação do ser humano, e isso simplesmente não existia. As crianças eram vistas e tratadas como adultos em miniaturas, e só começa a ter um olhar diferenciado a partir do final da Idade Média. $O$ autor ainda ressalta que nesse primeiro momento de atenção, a criança era tratada como uma forma - ou instrumento - de entretenimento e tratada com paparicacão, que só a partir do século XVII essas atitudes, após sofrerem muitas críticas, começaram a modificaram gradativamente.

Durante esse período chamado Idade Moderna por meados aos séculos XVII ao XIX a escola passa a ter um novo olhar a esse público infantil direcionando-os por meio das disciplinas com um fundo forte religioso inserido a esse processo o que permite notar crianças com responsabilidades e ainda vestimentas de adultos. O autor supracitado elenca que uma educação universalizada ainda era longe de se tornar real, por ainda haver defensores a uma educação diferenciada a classes sociais.

Com o desenvolvimento do Capitalismo e a necessidade da mão de obra, favorece então ao surgimento na Europa no final do século XVIII e início do século XIX as primeiras creches com a finalidade de guardar crianças de 0 a 3 anos durante o período de trabalho de seus pais. Ainda ressalta as autoras que no Brasil as creches surgem no final dos séculos XIX e metade do século $X X$, com o crescimento do país e a evolução industrial. (MATHIAS e PAULA, 2009).

O processo revolucionário ocorrido por volta dos séculos XVII e XVIII, período onde acontece tanto a revolução Inglesa 1640 a 1660 e mais tarde a Revolução Francesa influenciando várias transformações por todo mundo começando na Europa e chegando aos demais continentes; a urbanização e a implementação de novas tecnologias influenciam de maneira direta e indireta na vida da humanidade na busca de melhores oportunidades nos meios urbanos, as famílias viam na mão de obra assalariada a esperança de melhoria de vida, o que na verdade desencadeou uma nova classe social denominada de proletariado.

Fatores assim mencionados que influenciaram em uma educação para as crianças que outrora ocupavam espaços nas indústrias, pois os pais precisavam trabalhar para garantia de seus sustentos, incitando assim a inclusão dessas crianças nas escolas com fim de propiciar a mão de obra mais produtiva dos pais 
de famílias. Conforme falamos em orientação, acrescente aqui neste parágrafo, ou abra um próximo, mencionando a influência do capitalismo nas relações de trabalho entre empresas e chefes de famílias, e destes com a família, visto que em dado momento tais relações tem condicionado efeitos negativos quanto à inclusão da criança na escola.

Mediante todo esse processo evolutivo (ou não) muitos erros e acertos vêm sendo estudados na tentativa de um ensino aprendizagem que venha atender as necessidades evolutivas da criança dentro do contexto nomeado de Educação Infantil, pois os anseios de um atendimento de qualidade já era sentido por parte de alguns profissionais desde esse período histórico, como é afirmado por Craidy e Kaescher (2001):

Todo este conjunto de ideias, com os conflitos que existem entre elas,
vieram a influenciar as instituições que surgiam e marcaram de forma
muito forte as propostas e a forma de atuação dos educadores, em
cada creche e pré-escola. Outro dado que é preciso lembrar é que a
expansão destas instituições, especialmente no final do século XIX na
Europa e mais da metade do século XX no Brasil, recebeu também
grande influência das ideias dos médicos higienistas e dos psicólogos,
que traçavam de forma bastante estrita o que suas famílias que
deveriam ser consideradas normais ou patológicas. (CRAIDY e
KAESCHER, 2001, p.15).

É evidenciado que desde os séculos XX, havia uma necessidade de se pensar um atendimento adequado para não se falar ideal a essas crianças tão importantes coadjuvantes dessa etapa educacional chamado de Educação Infantil, pois a mesma trata da base estrutural de todo um processo formativo, tanto cognitivo como social, ou seja, a forma de tratamento oferecido a esse público poderá vir a ser uma das ferramentas na solução de vários fatores problemas que a atual Educação brasileira vivencia na contemporaneidade.

Educação Infantil no Brasil: os primeiros Passos Legais

No Brasil, não diferente da história mundial, alguns fatores se associam, porém com suas características próprias em relação à educação para crianças pequenas. "Até meados do século XIX, o atendimento de crianças pequenas longe da mãe em instituições como creches ou parques infantis praticamente não existia". (OLIVEIRA, 2011, P.91)

Ainda pontua a autora que a população do país nessa época era em maioria do meio rural e as crianças órfãs filhas de escravos ou indígenas fruto 
de relacionamento do homem branco por meio de exploração sexual, eram criados ali mesmo nas fazendas por famílias de fazendeiros. As crianças órfãs do meio urbano geralmente eram filhos de mães solteiras de famílias de prestígio social, as quais abandonavam essas crianças, e, as mesmas iriam parar nas 1"rodas de expostos".

Só a partir de meados do século XIX, essas situações começam a mudar e começam o surgimento de creches, asilos e internatos. As mesmas originam se com características assistencialistas com o objetivo de cuidar e proteger essas crianças cuja maioria proveniente de famílias carentes vistas do aspecto sócio econômico e também a partir da abolição da escravatura, crianças filhas de ex escravos e mães solteiras. Em sua maioria, essas primeiras instituições eram de responsabilidade de entidades religiosas.

As primeiras escolinhas para o público infantil receberam o nome de "Jardim de infância" um modelo americano e europeu. Em 1875 a 1877, surgem primeiro no Rio de Janeiro e depois em São Paulo, os primeiros jardins de infância sobe o cuidado de entidades privadas. Só mais tarde aparecem os jardins de infância públicos, porém seu atendimento ainda favorecia crianças advindas de famílias de alto escalão social. As programações pedagógicas eram inspiradas em Froebel (OLIVEIRA, 2011, p.93)

Com a criação da Lei de Diretrizes e Bases da Educação Nacional - LDB (Lei 4024/61) pela primeira vez a Educação infantil é referida nos artigos 23 e 24 Brasil, (1988):

\begin{abstract}
A educação pré-primária destina-se aos menores de até 7 anos, e será ministrada em escolas maternais e jardins de infância; [...] As empresas que tenham a seu serviço mães de menores de sete anos serão estimuladas a organizar e manter, por iniciativas próprias ou em cooperação com poderes públicos, instituições de educação préprimária. (BRASIL, 1988)
\end{abstract}

Tivemos também dez anos após a primeira lei, em 1971 a aprovação de uma segunda Lei de Diretrizes e Bases da Educação Nacional (LDB 5692/71), a qual nos traz o seguinte texto: "os sistemas valerão para as crianças de idade inferior a 7 anos que recebam conveniente educação em escolas maternais, jardins de infância ou instituições equivalentes" (BRASIL,1971).

\footnotetext{
${ }^{1}$ Cilindros ocos de madeira, giratórios, construídos em muros de igrejas ou hospitais de caridade que permitiam que bebês fossem neles deixados sem que a identidade de quem os trazia precisasse ser identificada para recolhimento dos "expostos".
} 
Logo então surge a Constituição Federal de 1988, a qual vem garantir o acesso por direito das crianças de 0 a 6 anos de idade em creches e também pré-escolas tendo por garantia em lei o atendimento a esse público como é referido na Constituição (BRASIL,1988, art. 208, inciso IV). Tal fato veio representar um momento histórico na educação brasileira, pois trazia em seu bojo o direito ao atendimento gratuito em creches e pré-escolas destacando ainda os direitos fundamentais da criança reconhecendo a mesma como sujeito portador de direitos a vagas em escolas com qualidade de ensino em iguais condições ao acesso e permanência.

Em 1990 esses dizeres são reafirmados com a criação do Estatuto da Criança e do Adolescente ECA (Lei n. 8.069/90) que vem regulamentar o artigo 227 da Constituição e no artigo 54, inciso IV, defendendo como o direito da criança a tais atendimentos educacionais em seus primeiros meses e anos de vida. Vejamos o que nos traz o texto Brasil (1988):

\footnotetext{
É dever da família, da sociedade e do Estado assegurar à criança e ao adolescente, com absoluta prioridade, o direito à vida, à saúde, à alimentação, à educação, ao lazer, à profissionalização, à cultura, à dignidade, ao respeito, à liberdade e à convivência familiar e comunitária, além de coloca-los a salvo de toda forma de negligência, discriminação, exploração, violência, crueldade e opressão (BRASIL, 1988).
}

A lei n. 8.069/1990 vem assegurar e valer o direito à educação infantil, norteando as políticas de atendimento a essa modalidade de ensino. Pois a mesma reconhece a criança como um sujeito ativo, em processo de desenvolvimento físico, psicológico, social e cognitivo com características próprias, reafirmando o dever e a responsabilidade do Estado juntamente ao poder público, família e sociedade a esse público infantil.

Com a aprovação da LDB, n. 9.394/96, sua aplicabilidade e seus ensejos para que a busca por alternativas na intensificação dos avanços à qualidade do atendimento a essa modalidade de ensino tão necessária por se tratar da primeira etapa de educação básica, a qual traz como finalidade principal o desenvolvimento integral das crianças de até 5 anos de idade com a complementação da ação familiar e da própria comunidade a qual a criança esteja inserida (BRASIL, 1996). 
Essa etapa é considerada pela lei supracitada, em seu artigo 29 a indissociabilidade entre o cuidar e o brincar sendo então o complemento dos ensinos e educação já de antemão oferecidos pela família. A mesma ainda é considerada a base para que a criança venha construir novos saberes futuros em modalidades seguintes da educação brasileira.

Atualmente o ensino brasileiro está composto das seguintes etapas:

\section{I - Educação Básica:}

- Educação Infantil;

- Ensino Fundamental;

- Ensino Médio.

II - Educação Superior:

- Licenciaturas;

- Bacharelados.

Já em 1998 o Ministério da Educação e Cultura - MEC, lança o Referencial Curricular Nacional para Educação Infantil (RCNEI), o qual objetiva norteando pautada mente a proposta:

\footnotetext{
Este documento constitui - se em um conjunto de referências e orientações pedagógicas que visam contribuir com a implantação ou implementação de práticas educativas de qualidade que possam mover e ampliar as condições necessárias para o exercício da cidadania das crianças brasileiras (BRASIL, 1998a, p. 13).
}

Com a preocupação em estar em vigor de maneira prática e eficaz, o Conselho Nacional de Educação (CNE) aprova a criação de mais um documento que vem para consolidar esse ensino necessário ao público da Educação Infantil. O mesmo vem em caráter norteador em consonância a prática pedagógica e ações procedimentais que deverão ser colocadas em ação pelas entidades e instituições de ensino voltadas a esse nível de educação.

Faz-se necessário em todos os âmbitos educacionais em que se referem ao grau, nível ou período como melhor compreender, de ensino, um direcionamento do que se devem ser trabalhados em termos conteúdistas e práticas um encaminhamento que norteei o que e como trabalhar em cada uma dessas etapas. 
Surge então no Brasil após a Constituição Federal, a qual foi um marco decisivo na sustentabilidade e encaminhamento à Educação Infantil, alguns documentos norteadores para efetivação dessa etapa tão importante na vida do sujeito. Os Currículos educacionais e especificamente em discussão no presente texto, dos quais podem se destacar as Diretrizes Curriculares para Educação Infantil, os Parâmetros Curriculares Nacionais para Educação Infantil e outros pareceres mais do CNE, Conselho Nacional de Educação os quais trazem em seus bojos a consolidação de todo esse processo por meio documental legalizado. (CNE/CEB,2009. №5).

Em recentes pesquisas bibliográficas a esses referidos documentos, permeia como indagação qual então a problemática dessa etapa de ensino de fundamental relevância a formação educacional e intelectual do sujeito, a qual essa é constante tema de discussões e relevantes mudanças. Seria então a não efetivação dessa proposta documental por esses órgãos responsáveis ou seria a pratica pedagógica exercida dentro desses órgãos educacionais que o ofertam.

Ambas as documentações trazem a relevância clara e compreensível ao leitor em suas propostas pedagógicas, princípios fundamentais dos quais evidenciam as formas que devem ser então trabalhados.

\footnotetext{
São princípios das propostas pedagógicas: éticos (autonomia, da responsabilidade, da solidariedade e do respeito ao bem comum, ao meio ambiente e às diferenças culturais); políticos (dos direitos de cidadania, do exercício da criticidade e do respeito à ordem democrática) e estéticos (da sensibilidade, da criatividade, da ludicidade e da liberdade de expressão nas diferentes manifestações artísticas e culturais) (TUTTMAN, 2009,p.15)
}

Cabe então um olhar à criança como um ser social e histórico, dotado de habilidades cognitivas e sentimentais onde valores sociais, éticos, políticos e estéticos devem ser estimulados já no início de sua trajetória educativa escolar.

Os Parâmetros Curriculares Nacionais de Qualidade para Educação Infantil - Volume 1 (p.13) trazem um direcionamento onde a criança não deve ser tratada como algo que já nasce pronto e acabado ou vice verso, vazio e carente dos elementos entendidos como necessários à vida adulta ou até esse ser tenro receba em tempo cabível ações exteriores que venha suprir e estimular mesmo que o seu conhecimento dar se por iniciativa própria. 
O estimulo e a intervenção pedagogia de maneira a se direcionar por meio do currículo faz se de uma necessidade vital para que seu processo evolutivo de conhecimento em toda amplitude física, social e psicológica.

Ao se levar esses fatores em conta, aspectos da pedagogia infantil não devem ser perdidos de vistas durante a prática diária e constante dessa etapa. Para essa efetivação os $\mathrm{PCN}$ de qualidade volume 1 aponta algumas propostas como:

a) Objetivos;

b) Concepção;

c) Organização de espaço, tempo e matérias;

d) Diversidade;

e) Eixos norteadores do currículo;

f) Avaliação e

g) Transição para o ensino fundamental.

Onde cada proposta, também chamada de Valores objetivados no documento, traz especificadamente como e, o que deve ser feito em cada ponto direcionador, tanto para as instituições de ensino e todo seu corpo técnico e pessoal como também a todos órgãos envolvidos de modo direto ou indiretamente para que de fato esse ensino seja efetivado como deve ser.

Pois os mesmos têm o objetivo geral de orientar as políticas públicas na área de elaboração de todos os planejamentos, execução e avaliação das propostas pedagógicas, com intuito de promoverem o desenvolvimento integral de crianças de 0 a 5 anos de idade, considerando as pesquisas literárias e experiências que comprovam que as crianças constroem a sua identidade coletiva e pessoal, imagina, brinca, deseja, fantasia, observa, narra, experimenta, questiona e constrói sentidos sobre a natureza e a sociedade na qual está inserida produzindo dessa forma cultura. (TUTTMAN, 2009, p.15).

Ou seja, são seres atuantes providos de capacidade sensoriais intelectuais ativas e influentes no meio ao qual estão inseridas. 


\section{MATERIAIS E MÉTODOS}

\section{A ATUAL REALIDADE DA EDUCAÇÃO INFANTIL NA REDE PÚBLICA MUNICIPAL DE ITAPURANGA GOIÁS}

Por entender que se faz necessário um estudo real dessa prática educativa de ensino na primeira etapa que corresponde a faixa etária dos 0 aos 05 anos de idade BNCC 2018. No período de seis meses foi feito um estudo em loco nas escolas da rede Municipal de Educação de Itapuranga Goiás.

Um estudo documental e coleta de dados via entrevistas a profissionais envolvidos. Este tema deu por necessidade de sanar um questionamento que surgiu no período que estava cursando o mestrado e mediante o atual cenário educacional passando por mudanças mediante a construção, aprovação e consolidação da nova BNCC, principalmente no tocante a parte referida e direcionada a Educação Infantil.

O então citado Munícipio foi campo para um estudo sobre a Educação Infantil, primeira etapa da Educação básica. A qual é de responsabilidade do município segundo a LDB, 1996 art. 29.

Atualmente o Município possui sob sua responsabilidade quatro (04) escolas municipais e duas Creches Municipais, as quais foram in locos do estudo sobre a Educação Infantil.

Escola Municipal Vera Cruz possui 826 alunos sendo 247 da Educação Infantil, seu Projeto Político Pedagógico traz a concepção Vygotsckyana, ou seja, sócio interacionista e dentro das finalidades e objetivos em relação a Educação Infantil, garantir o acesso, a permanência e a promoção dos alunos na Educação Infantil, atendendo necessidades da comunidade, com previsão até/ 2019, e no Ensino Fundamental, oferecendo oportunidades àqueles educandos que apresentam dificuldades de aprendizagem através do reforço escolar no turno ampliado.

A Escola Municipal Vera Cruz possui duas unidades de atendimento, na unidade polo há apenas quatro turmas de E.I., por atender a Educação Básica da primeira etapa, ou seja, do primeiro ao quinto ano as salas que atendem as crianças da E.I. não são adaptadas a faixa etária delas. Já na unidade dois, onde se encontra um número significante de crianças da E.I., possui oito turmas de 
E.I., portanto nessa unidade os mobiliários são adequados a atender essa faixa etária de ensino.

A Escola Municipal Betel possui 252 alunos sendo 70 da Educação Infantil, é uma unidade Municipal responsável por outras 04 (quatro) unidades. Possui um total de 05 (cinco) pedagogas atuando na E.I. pois devido ao número baixo de estudantes nessa etapa educacional, nessa referida escola e suas outras 04 (quatro) unidades as turmas de jardim I e Jardim II funcionam em forma de multisseriadasí.

O Projeto Político Pedagógico da referida unidade educacional municipal, em referencia a E.I. traz em seu bojo em sua concepção Filosófica e Pedagógica, o desejo de uma sociedade cujo pensamento, práticas e valores estejam baseados em objetivos positivos; uma sociedade na qual cada indivíduo exerça sua capacidade de decisão e conquiste sua liberdade com os outros, embora não possa estar livre integralmente das instituições sociais também baseados nas novas tendências educacionais.

Com relação a E. I. há salas cujo mobiliário não é adequado a faixa etária e percebe se também que dentro do PPP, dessa unidade escolar não há uma clareza na escolha da concepção pedagógica e não há nenhum item direcionado com exclusividade a etapa da E.I. Ambas propostas estão aglomeradas em um todo

\section{CONCLUSÃO}

Os fatores que integram a formação do EU (Professor - Aluno), tais como os biológicos, afetivos, sociais e emocionais os tornam únicos, agindo em prol de buscas extraordinárias, em direção da percepção que tem de si mesmos, dos outros, enquanto colaborador da construção de relações interpessoais mais saudáveis e do mundo em que vivem. Essa ideia nos garante olhar com esperança para um futuro possível a partir de um processo permanente de construção ativa e criativa.

Ao longo de nossa pesquisa fomos impulsionados a repensar nossa prática educacional e convidados a escrever uma nova história pautada na fusão da constituição humana, exatamente onde tudo ou nada pode acontecer em relação aos níveis de aprendizagem que se perpetuam no ser. Tais 
aprendizagens são elaboradas e reelaboradas em cada oportunidade para atuação pedagógica de cada interlocutor da Educação Infantil.

Diante do cenário pesquisado, a escola deve ser a protagonista e cumprir com sua razão de ser, intermediadora e facilitadora da formação de novos cidadãos. Aqui cabe uma tomada de atitude, ressignificar a educação e suas práticas de modo que sejam estabelecidas conexões verdadeiras e profundas com os interlocutores da educação, considerando a realidade histórico-cultural de cada município, assim como a relação interpessoal afetivo-cognitiva em vista de movimentar o processo responsável pela aquisição de novos conhecimentos.

Pesquisar sobre "A Importância da Educação Infantil como base fundamental ao Processo de Aprendizagem em Itapuranga - GO ajudou-nos refletir sobre a relevância do conhecimento teórico enquanto possibilidade para suscitar a sensibilidade que devemos cultivar em relação às diversas formas de ensino-aprendizagem que desperta enxergar cada aluno em sua concretude e totalidade.

Partindo da revisão do contexto escolar na atualidade, muitas escolas continuam dominadas pela concepção pedagógica tradicional, onde a Educação Infantil ainda é tida como assistencialista, o ensino muitas vezes é realizado de forma empírica tradicionalista acarretando grandes consequências negativas, principalmente para aquele que é o alvo da aprendizagem: o educando.

Consideramos que de fato a Educação Infantil é a base fundamental ao processo de Aprendizagem em Itapuranga - GO; que a formação do Profissional de Educação Infantil ligada às práticas do cuidar e do educar pode ser considerada relevante como espaço do brincar na Educação Infantil; e que, as tendências pedagógicas na Educação Infantil através do Lúdico suscitam práticas inspiradoras e transformadoras, contribuindo eficientemente e eficazmente com o processo de ensino-aprendizagem de cada interlocutor ligado à educação.

A pesquisa poderá contribuir com as Escolas do Município de Itapuranga - GO e Região, quiçá no âmbito nacional, apontando caminhos possíveis para a superação das mais variadas demandas tais como: Importância da Educação Infantil na Rede de Ensino; desenvolver ações concretas a partir de uma construção mais humanizada tendo em vista as Relações Interpessoais enquanto potencial para a implementação de projetos pedagógicos ativos e 
criativos que contemplem a integração, estratégia e subjetivação, promovendo assim o bem estar entre os interlocutores da Educação, a formação e qualificação dos docentes em prol de experiências educacionais que imprimem caráter de continuidade.

\section{REFERÊNCIAS}

ALMEIDA, Laurinda Ramalho de, (2000). Wallon e a Educação. In: Henri Wallon - Psicologia e Educação. São Paulo: Loyola.

ANGOTTI, Maristela (org.). Educação Infantil: para que, para quem e por quê?. 4. ed. Campinas: Alínea, 2014.

ARIÈS, Philippe. História Social da Criança e da Família. 2ª . Ed. Rio de Janeiro; LTC, 1981 .

ARROYO, Miguel. Profissão de mestre. São Paulo: Cortez, 2004.

BRASIL. Ministério da Educação e do Desporto. Secretaria de Educação Fundamental. Referencial curricular nacional para a educação infantil/Ministério da Educação e do Desporto, Secretaria de Educação Fundamental. - Brasília: MEC/SEF, 1998, volume: 1 e 2.

BRASIL. Ministério da Educação e do Desporto. Secretaria de Educação Fundamental. Diretrizes Curriculares Nacionais para a Educação Infantil. Brasília, DF: MEC/SEF/COEDI, 2009.

LEI no 9.394 de 20 de dezembro de 1996. Estabelece as Diretrizes e Bases da Educação Nacional.

.Estatuto da Criança e do Adolescente. CBIA ,1990.

Ministério da Educação. Câmara de Educação Básica do Conselho Nacional de Educação. Diretrizes Curriculares Nacionais para Educação Infantil.1999.

INEP. Instituto Nacional de Estudos e Pesquisas Educacionais Anísio Teixeira. Educação Infantil é um dos maiores desafios do Plano Nacional de Educação. htt://portal.inep.gov.br/.2004. Acessado em 22/11/2018. 
BROUGÈRE, G. Brinquedo e cultura. 8. ed. São Paulo: Cortez, 2010.

CARDODSO, Bruna Puglisi de Assumpção. Práticas de Linguagem Oral e Escrita na Educação Infantil. São Paulo. Ed. Anzol 2012.

CARVALHO, A.M.C. et al. (Org.). Brincadeira e cultura: viajando pelo Brasil que brinca. São Paulo: Casa do Psicólogo, 1992.

COLL, C.; PALACIOS, J.; MARCHESI, Á. (Orgs.). Desenvolvimento Psicológico e Educação. Porto Alegre: Artes Médicas, 1995.

CRAIDY, Maria; II KAERCHER, Gládis Elise P. da Silva. Porto Alegre: Artmed, 2001.

FREIRE, Paulo. Extensão ou comunicação. 10 ed. Rio de Janeiro: Paz e Terra, 1992.

Pedagogia da Autonomia: saberes necessários à prática educativa. 44a. Ed. Rio de Janeiro: Paz e Terra 2013.

GALVÃO, I. Henri Wallon: uma concepção dialética do desenvolvimento infantil. 17

ed. Petrópolis: Vozes, 2008.

GARCÍA, R. O conhecimento em construção: das formulações de Jean Piaget à teoria de sistemas complexos. Porto Alegre: Artmed, 2002.

GAUTHIER, Jacques. $O$ que é pesquisar: entre Deleuze e Guattari e o candomblé. Pensando mito, ciência, arte e culturas de resistência. Educação e Sociedade, Campinas, ano XX, n. 77, dez. 1999.

GOLDSHMIED, Elionor; SONIA, Jackson. Educação de 0 a 3 anos: 0 atendimento em creche._2. Ed - Porto Alegre; Artmed, 2006.

HOFFMAN, Jussara. Avaliação e Educação infantil: um olhar sensível e reflexivo sobre a criança. Ed. Atualizada e Ampliada. Porto Alegre,Mediação 2012.

HUIZINGA, J. Homo Ludens. 4. ed. São Paulo: Perspectiva, 1996, 236p. 
ISAIA, Silvia. Processo formativo docente. Verbete. Enciclopédia de pedagogia universitária. Brasília: MEC/INEP, 2006, p. 351.

KESSELRING, T. Jean Piaget. Petrópolis: Vozes, 1993.

MAHONEY, Abigail Alvarenga, (2000). Introdução. In: Henri Wallon - Psicologia e educação. São Paulo: Loyola.

MAHONEY, A. A.; ALMEIDA, L. R. de. Afetividade e processo ensinoaprendizagem: contribuições de Henri Wallon. Psicologia da educação, v. 20, p. 11-30, 2005. ISSN 1414-6975.

MARCONDES, K. H. B. Continuidades e descontinuidades na transição da Educação Infantil para o Ensino Fundamental no contexto de nove anos. Tese (Doutorado em Educação Escolar). Universidade Estadual Paulista, Araraquara, 2012.

MATHIAS, Eliane Cristina Bio, PAULA, Sandra Nazareth. A Educação Infantil no Brasil: Avanços, desafios e políticas públicas. Revista Interfaces: ensino, pesquisa e extensão ano 1. № 1.2009. Disponível em: <http:www.revistainterfases.com.br/ed. /1/1 - 5. Pdf >. Acesso em 05. 05. 2018.

MORRIS, Charles G. MAISTO, Albert . Introdução à Psicologia. São Paulo; Prentice Hall, 2004.

MOSQUERA, Juan. O professor como pessoa. Porto Alegre: Sulina, 1976.

OLIVEIRA, Vera Barros de (org). O brincar e a criança do nascimento aos seis anos. Petrópolis, RJ: Vozes, 2000.

OLIVEIRA, Z. de M. R. de. O currículo na educação infantil: o que propõem as novas diretrizes nacionais? In: I Seminário Nacional: Currículo em movimento Perspectivas atuais, 2010, Belo Horizonte. Anais do I Seminário Nacional: currículo em movimento. Perspectivas atuais. Belo Horizonte: Universidade Federal de Minas Gerais, 2010. v. 1. p. 1-20.

OLIVEIRA, Zilma de Moraes Ramos. Educação Infantil: fundamentos e métodos. 7. ․ㅡ. ed. São Paulo: Cortez 2011. 
PIAGET, J. Desenvolvimento e aprendizagem. Traduzido por Paulo Francisco Slomp do original In. LAVATTELLY, C. S. e STENDLER, F. Reading in child behavior and development. NewYork: Hartcourt Brace Janovich, 1972.

. Epistemologia Genética. Petrópolis: Vozes, 1970. - (EG)

- (SEP)

Seis estudos de psicologia. Rio de Janeiro: Forense Universitária, 1971.

A equilibração das estruturas cognitivas. Rio de Janeiro: Zahar, 1976.

. Biologia e conhecimento: ensaio sobre as relações entre as regulações orgânicas e os processos cognoscitivos. Petrópolis: Vozes, 1996.

SAVIANE, Dermeval. Educação Brasileira: estrutura e sistema.11. ed.rev. Campinas SP: Autores Associados,2012.

SOLÉ, Isabel. Estratégias de Leitura. 6ª . Ed. Porto Alegre. Artmed 1998.

WALLON, H. Do ato ao pensamento: ensaio de psicologia comparada. Petrópolis: Vozes, 2008.

A evolução psicológica da criança. São Paulo: Martins Fontes, 2007.

As origens do pensamento na criança. São Paulo: Manole, 1986.

. Psicologia e Educação da Infância. Lisboa: Estampa, 1975.

. Do acto ao pensamento. Lisboa: Moraes, 1979.

ZANLUCHI, Fernando Barroco. O brincar e o criar: as relações entre a atividade lúdica e o desenvolvimento da criatividade e educação. Londrina, PR: O autor, 2005. 